\title{
ROL DEL MAESTRO EN LA REALIDAD EDUCATIVA ACTUAL
}

\author{
Yoselin Guerrero Rivera
}

\begin{abstract}
RESUMEN
La educación actual en el Perú presenta diversas problemáticas que perjudican el desarrollo pleno de las potencialidades de los estudiantes; sin embargo, los maestros debemos concebirlas como puntos de partida para planificar nuestro trabajo en aulas.
\end{abstract}

En primer lugar, es importante que los maestros tengamos claridad en cuanto a la línea orientativa que seguiremos para aplicar las diversas estrategias y métodos en nuestra continua práctica pedagógica.

En segundo lugar, se debe aplicar estrategias que nos permitan captar la atención del estudiante y orientarlo hacia el desarrollo de sus capacidades.

En tercer lugar, es importante desarrollar en ellos no solo la parte cognitiva, sino también la parte emocional y creativa.

Solo así lograremos formar jóvenes para el futuro.

\section{PALABRAS CLAVE}

Educación, realidades, inteligencia, competencias, estrategias.

\section{ABSTRACT}

The current education in Peru presents several problems which affect the full development of the potential of students. Nevertheless, teachers must understand them as starting points to plan our work in classrooms.

First, it is important for teachers to be clear about the guideline we will follow to apply several strategies and methods in our ongoing pedagogical practice.

Secondly, strategies must be applied that allow us to capture the student's attention and guide him towards the development of his capacities.

Thirdly, it is important to develop in them not only the cognitive part, but also the emotional and creative part.

Only in this way will we be able to form young people for the future.

\section{KEYWORDS}

Education, realities, intelligence, skills, strategies.
$\mathrm{P}$ aíses como Finlandia, concebido por toda una década como el país con el mejor modelo educativo del mundo de acuerdo a PISA, resulta que ya no es pionero en la lista de países con los mejores resultados, destacándose ahora los países asiáticos. ¿A qué podría deberse este cambio? ¿Es ahora el modelo asiático el más indicado para servir de modelo por sus asombrosos resultados en las últimas pruebas? ¿Qué hace que los países obtengan buenos o malos resultados? ¿Se debe a la propuesta educativa? ¿Se trata simplemente de qué tan preparados estén para rendir una prueba PISA?

Lo cierto es que cada país orienta sus intereses a alcanzar sus propios objetivos, unos buscan con la educación alcanzar una mejor calidad de vida, otros a ser punteros en pruebas estandarizadas y otros a imitar modelos extranjeros. Pues bien, lo cierto es que nuestro país ha buscado durante años imitar una educación ideal que hasta hoy no resulta beneficiosa si buscamos estandarizarla, dejando de responder a las nuevas problemáticas que invade nuestro sistema educativo.

En mi opinión, solo podremos lograr mejorar la educación peruana aterrizando en nuestra realidad y dando soluciones creativas e innovadoras para lograrlo. Atrás quedaron los métodos tradicionales que respondían a patrones distintos de nuestros estudiantes. Ellos traen nuevas potencialidades, pero a su vez nuevos retos a los que los maestros estamos llamados a superar. 


\section{ANÁLISIS}

Los tiempos de hoy han dado un giro tremendo comparado con décadas anteriores, las problemáticas que hoy agobian nuestro sistema educativo y a nuestros estudiantes son otras.

En primer lugar, los cambios en cuanto a la tecnología y los malos usos que a esta se le da: el uso excesivo de los chats interactivos, las redes sociales, etc., cada vez más están atentando contra la comunicación directa, afectiva y rica que una vez estuvo presente en las reuniones familiares y amicales. No está demás mencionar también el contenido poco cuidado al que se puede acceder permitiendo que la intimidad del ser humano esté cada día más invisible ante los ojos del mundo, acarreando otras consecuencias como el acoso y el bullying.

En segundo lugar, la sociedad de hoy está mucho más globalizada y los jóvenes buscan encontrarse en uno de estos modelos concebidos como ídolos, siendo estos un modelo aparentemente ideal para ellos. Por otro lado, los excesos, los vicios como el alcohol y las drogas, los videojuegos y el libertinaje, padres ausentes, entre otros, hace que los jóvenes se hallen aún más desorientados, sin contar con una imagen paternal que los sepa guiar en ese camino lleno de confusión.

Y finalmente, como consecuencia de lo anteriormente dicho, los jóvenes de hoy se muestran mucho más independientes, y muchos de ellos, ansiosos e irritable, siendo estas características las que observamos día a día en nuestras aulas de clase y con las que luchamos para poder cumplir con nuestro papel de maestros.

En ese sentido es que nos planteamos las siguientes preguntas: ¿Estamos los maestros preparados para estas nuevas generaciones? ¿Somos capaces de guiar a nuestros estudiantes para que logren sus objetivos en la vida? ¿Somos realmente conscientes de cuál es nuestro papel en el aula?

Hace unos días escuché a una maestra decir: "Mis chicos siempre se portan así, nunca van a cambiar" y recordé una frase que medio siglo atrás presentaba Albert Einstein "Locura es hacer la misma cosa una y otra vez esperando obtener diferentes resultados". Entonces, le pregunté: ¿qué piensas hacer? Y ya no vi más que un gesto resignado y evasivo.

Sabemos que hay miles de factores que interfieren con la educación de nuestros estudiantes, pero es nuestro deber tomar un papel fundamental de este proceso. Somos maestros, somos creativos, innovadores y firmes para alcanzar nuestros objetivos. Empecemos, pues, por observar a nuestros estudiantes en clase y empezar a trabajar.

Antes de poner las manos a la obra debemos tener presente lo siguiente "Pensamos, sentimos y actuamos de manera diversa, dependiendo del contexto social y cultural en el que nos correspondió nacer. Asimismo, también podríamos decir que al pensar, al sentir y al amar utilizamos competencias e instrumentos relativamente diferentes" (De Zubiría 2013:12).

En ese sentido debemos responder a estas nuevas exigencias.

Lo primordial es definir nuestra línea de trabajo basada en un determinado enfoque, principios, teorías del aprendizaje y métodos eficaces, lo cual nos permitirá tener mayor claridad en nuestra labor y una justificación razonable para lo que hacemos día a día.

Es importante también elegir una metodología distinta para cada grupo humano con el que trabajamos, pues estos poseen características diferentes que lo hacen ser únicos: unos más activos que otros, con distintos estilos y ritmos de aprendizaje, etc., lo cual debe ser un punto de partida para la elaboración de nuestro plan de trabajo.

Una vez que tenemos claro cuál es la metodología a emplear, es importante definir qué técnicas usar para captar la atención de nuestros estudiantes, lo cual es concebido como un gran reto debido a las características de los mismos. Una vez que lo hayamos conseguido es indispensable saber que esta no durará por mucho tiempo, por tanto debemos tratar de que se produzca aprendizaje en 
estos momentos y icómo se realiza esto de manera eficiente? Generando emociones positivas. Según el aporte de las neurociencias, un estudiante aprende cuando se activan emociones en su cerebro. De esta manera, activamos una emoción e introducimos el aprendizaje. De esta forma, lo aprendido perdurará en la memoria fijándose en ella para siempre.

En un primer momento, es indispensable motivar al estudiante teniendo en cuenta sus intereses, generar actividades diversas: usar videos, audios, lecturas, imágenes, juegos interactivos, etc. En ese sentido, es mucho más significativo cuando se usan actividades lúdicas al aire libre, pues generamos expectativa y emociones positivas para generar aprendizaje. Posteriormente, debemos intentar generar un conflicto, un desequilibrio, para luego acomodar el nuevo aprendizaje y volver al equilibrio con un nuevo conocimiento. Este conflicto cognitivo debe partir de sus saberes previos, pues es la única manera de que se interese por lo que escucha y que esto tenga un sentido para él, esto se logra a través de preguntas, y repreguntas, poniéndoles retos, desafíos, preguntas que despierten dudas y generen confusiones para luego orientarlos a generar un nuevo conocimiento.

En un segundo momento, es importante tener en cuenta que para que el estudiante realmente aprenda se requiere hacer sus experiencias lo más vivenciales posibles, ya que solo partiendo de la experiencia propia e individual se logran los aprendizajes, y es que se aprende mucho más si partimos de nuestras propias vivencias que si retomamos las vivencias de otros (De Zubiría 2013).

En ese sentido, debemos aprovechar los ambientes libres, el patio, las canchas deportivas, etc. Y no olvidar que es importante tener un buen dominio del grupo, fijar reglar claras y consensuadas. Asimismo, aplicar estrategias novedosas orientadas hacia el desarrollo de competencias, mas no de contenidos, por tanto se sugiere propiciar la investigación: elaboración de ensayos, artículos de opinión, debates orales, foros, exposiciones, experimentación científica, etc. Nuestros estudiantes deben ser el centro de todo, por tanto son ellos quienes elaboran, quienes crean, quienes concluyen, etc. Los maestros tenemos la labor de guiarlos, de cuestionarlos para que ellos lleguen al aprendizaje por símismos.

Por otro lado, es importante desarrollar en los estudiantes no solo la parte cognitiva sino también el aspecto emocional, tal como lo mencionan De Zubiría y Ramirez (2005), citados por De Zubiría (2013):

Nuestras investigaciones nos permiten concluir que, antes que el CI, en el rendimiento escolar de un estudiante tienen un papel mucho más importante la autonomía, el interés por el conocimiento, la creatividad, la reflexividad y la resonancia familiary escolar (p. 17).

Es importante, entonces, desarrollar ambas caras dela educación.

Debemos empezar por crear un ambiente físico atrayente, adornado con colores vivos, rodeado de paneles, murales y trabajos elaborados por ellos mismos. Asimismo, trabajar en un aula limpia y ordenada, con adecuada iluminación y ventilación.

Se debe tener muy presente el desarrollo de los valores, de tal manera que al planificar nuestras clases debemos pensar en cómo insertar el desarrollo de actitudes que demuestren algún valor que hoy en día se está dejando de lado. En ese sentido, es importante reflexionar con los estudiantes, si es posible al finalizar la clase, sobre los valores que hoy en día se están perdiendo y sobre lo que hoy pusieron en práctica para cambiar esa realidad. Debemos recordar que nuestro rol debe orientarlos para la vida y en ella hoy en día hay un escaso desarrollo de estos valores.

Asimismo, debemos reforzar en nuestros estudiantes sus diversas inteligencias, el talento y la creatividad que cada uno posee, pues son ellas las que juegan un papel importantísimo al desempeñarse en un mundo social laboral. Pues tal como lo dijo Gardner (1987), citado en Armstrong (2012): 
"Es de suma importancia que reconozcamos y alimentemos todas las inteligencias humanas y todas las combinaciones de inteligencias. Todos somos tan diferentes en parte porque todos poseemos combinaciones distintas de inteligencias. Si reconocemos este hecho, creo que al menos tendremos más posibilidades de enfrentarnos adecuadamente a los numerosos problemas que se nos plantean en esta vida" (p. 9).

Es así que resulta fundamental tener en cuenta las inteligencias que cada estudiante posee.

Asimismo, somos los maestros quienes estamos llamados a inculcar y potenciar el talento en nuestros estudiantes, pues la inteligencia y el talento dependen esencialmente de la interacción entre el niño, los mediadores y la cultura. Los niños y los jóvenes se vuelven más inteligentes y talentosos, fundamentalmente gracias a la calidad en la mediación de la cultura que ellos tuvieron la fortuna de recibir (De Zubiría 2013).

La sociedad de hoy no requiere personas llenas de conocimientos, sino personas capaces de dar soluciones, personas innovadoras y creativas y hacia ello es que los maestros debemos apuntar.

\section{CONCLUSIONES}

Nuestro país exige un cambio en todos los ámbitos de la educación; sin embargo, como docentes tenemos la misión de responder a las nuevas demandas educativas que exigen de nosotros mayor preparación, innovación y firmeza para formar estudiantes líderes, autónomos y creativos.

Desde nuestras aulas podemos hacer cosas increíbles. Tener en cuenta sus diferencias, sus modos de aprender, sus potencialidades y la realidad en la que vivimos, nos servirán de mucho para ayudarlos a alcanzar sus objetivos de vida.

\section{REFERENCIAS}

Armstrong, T. (2012). Inteligencias múltiples en el aula: Guía práctica para educadores. España: Paidós.

De Zubiría, J. (2013). ¿Cómo diseñar un currículo por competencias?: Fundamentos, lineamientos y estrategias. Colombia: Magisterio.

De Zubiría, J. (2013). Mitos y realidades sobre la inteligencia y el talento. Investigación educativa, 17 (2), 11-20. 